\title{
The Differential Diagnosis and Treatment of Atypical Parkinsonism
}

Johannes Levin, Alexander Kurz, Thomas Arzberger, Armin Giese, Günter U. Höglinger

\section{SUMMARY}

Background: Aside from idiopathic Parkinson syndrome (Parkinson's disease), there are a number of other, so-called atypical parkinsonian syndromes: dementia with Lewy bodies (DLB), multiple system atrophy (MSA), progressive supranuclear palsy (PSP), and corticobasal degeneration (CBD). DLB is a common disease, with a prevalence of $0.4 \%$ (400 cases per 100000 persons) in the elderly; MSA and PSP both have a prevalence of 5 to 10 per 100000 persons, while the prevalence of CBD is about 1 per 100000 .

Methods: This review is based on pertinent publications retrieved by a selective literature search.

Results: The atypical parkinsonian syndromes are synucleinopathies and tauopathies, i.e., disorders characterized by the abnormal deposition of the proteins a-synuclein and tau. The site of deposition is correlated with the clinical features. In DLB, synuclein is mainly deposited in neocortical neurons, with some brain stem involvement as well. The main clinical features are dementia and, later on, parkinsonism. In MSA, synuclein is deposited in oligodendrocytes, mainly in the cerebellum but also in the brain stem; the main clinical feature is autonomic dysfunction combined with parkinsonism or cerebellar ataxia.

Synucleinopathies often impair REM (rapid eye movement) sleep. PSP and CBD, on the other hand, are primary tauopathies. PSP usually causes predominantly supranuclear vertical gaze palsy and early postural instability with falls, less commonly parkinsonism (PSP-P) or frontotemporal dementia (PSP-FTD) as its most prominent feature. CBD typically manifests itself as markedly asymmetrical parkinsonism with apraxia or cortical sensory disturbance. At present, there is no accepted causal treatment for any of these disorders; the available symptomatic treatments are of limited efficacy and are supported only by lowlevel evidence.

Conclusion: Causal treatments for neurodegenerative diseases are now being developed and tested, and thus a molecular diagnosis is desirable. This will require the cooperation of primary care physicians with specialized centers.

\section{Cite this as:}

Levin J, Kurz A, Arzberger T, Giese A, Höglinger GU: The differential diagnosis and treatment of atypical parkinsonism. Dtsch Arztebl Int 2016; 113: 61-9. DOI: 10.3238/arztebl.2016.0061

Department of Neurology, Klinikum rechts der Isar, Technische Universität München and Chair for Translational Neurodegeneration, German Center for Neurodegenerative Diseases (DZNE), Munich: Prof. Dr. med. Höglinger

Department of Neurology, Ludwig-Maximilians-Universität München, German Center for Neurodegenerative Diseases (DZNE), Munich: PD Dr. med. Levin

Department of Psychiatry and Psychotherapy, Klinikum rechts der Isar, Technische Universität München: Prof. Dr. med. Kurz

Center for Neuropathology and Prion Research (ZNP), Ludwig-Maximilians-Universität München: Dr. med. Arzberger, Prof. Dr. med. Giese

Department of Psychiatry and Psychotherapy, Ludwig-Maximilians-Universität München: Dr. med. Arzberger arkinsonism is defined as a combination of the key symptom bradykinesia with rigidity, tremor, or postural instability. Except for secondary forms of parkinsonism, in which the causes-for example, medication side effects, normal pressure hydrocephalus, and vascular encephalopathy-are discernible and may even be eliminated, parkinsonian syndromes are the sequelae of neurodegenerative disorders. The most common neurodegenerative parkinsonian syndrome is known as Parkinson's disease (PD) or idiopathic Parkinson syndrome, if it occurs sporadically (not familial) and its lead clinical symptom is a movement disorder subsequent to brainstem-predominant $\alpha$-synuclein deposition. In order to distinguish them from Parkinson's disease, other sporadic entities have been named atypical parkinsonian syndromes or atypical parkinsonism. The present review article describes current standards for the diagnosis and treatment of the most important disease entities in this latter group: dementia with Lewy bodies (DLB) (Table 1), multiple system atrophy (MSA) (Table 2), progressive supranuclear palsy (PSP) (Table 3), and corticobasal degeneration (CBD) (Table 4). In the following, we will discuss the differential diagnoses of and therapeutic appraches to atypical parkinsonism.

\section{Methods}

A selective literature search in PubMed was conducted from 1960 onwards, based on the authors' own scientific and clinical experiences. We included reviews, meta-analyses, randomized controlled trials, cohort studies, case-control studies, guidelines, and case reports.

\section{Neuropathology and pathophysiology}

Atypical parkinsonian syndromes are neurodegenerative disorders with intracellular deposition of amyloidogenic proteins. DLB, MSA, and PD are characterized by the abnormal deposition of the protein $\alpha$-synuclein (and therefore referred to as synucleinopathies); in PSP and CBD the tau protein causes damage and these entities are therefore referred to as tauopathies (1-3) (Figure 1). In PD and DLB, $\alpha$-synuclein aggregates are found in neurons, and in MSA these are found primarily in oligodendrocytes. In PSP and CBD, tau aggregates affect neurons, but also oligodendrocytes and astrocytes. The morphology of astrocytic tau deposits is what distinguishes PSP from 


\begin{tabular}{|c|c|}
\hline Areas & Findings/recommendations \\
\hline Neuropathology & $\begin{array}{l}\text { Aggregates of a-synuclein in neuronal somata (Lewy bodies) and processes (Lewy neurites) in typical } \\
\text { distribution (neocortex and brain stem) }\end{array}$ \\
\hline \multirow[t]{2}{*}{ Clinical syndrome } & $\begin{array}{l}\text { Dementia: cognitive impairments (attention, executive functions, visuospatial skills) with relevance to } \\
\text { activities of daily living }\end{array}$ \\
\hline & $\begin{array}{l}\text { At least one of the following key characteristics: } \\
\text { - Parkinsonian syndrome, onset after or at most } 12 \text { months before onset of dementia } \\
\text { - Fluctuations in alertness and attention } \\
\text { - Repeated visual hallucinations }\end{array}$ \\
\hline \multirow[t]{2}{*}{ MRI results } & Normal medial temporal lobes, in contrast to Alzheimer's dementia \\
\hline & $\begin{array}{l}\text { Rule out symptomatic causes, for example, vascular encephalopathy, } \\
\text { normal pressure hydrocephalus, aqueductal stenosis, encephalitis, tumor }\end{array}$ \\
\hline Basic diagnostic evaluation & $\begin{array}{l}\text { Neuropsychological tests, early visuospatial impairment (clock-drawing test, figure copying test), } \\
\text { impaired speech (naming, verbal fluency), executive dysfunction, recommended Montreal Cognitive } \\
\text { Assessment (MoCA), Frontal Assessment Battery (FAB); memory impairments may occur at a later } \\
\text { stage }\end{array}$ \\
\hline \multirow{4}{*}{$\begin{array}{l}\text { Extended diagnostic } \\
\text { evaluation }\end{array}$} & ${ }^{123}$ I-FP-CIT-SPECT $/{ }^{18} \mathrm{~F}$-Dopa-PET: striatal dopaminergic denervation \\
\hline & ${ }^{99} \mathrm{TC}-\mathrm{HMPAO}-\mathrm{SPECT} /{ }^{18} \mathrm{FDG}-\mathrm{PET}$ : occipital hypometabolism \\
\hline & ${ }^{123}$ I-MIBG-SPECT: cardiac noradrenergic denervation may occur \\
\hline & Sleep laboratory: where applicable, rapid eye movement (REM) sleep behavior disorder \\
\hline \multirow[t]{4}{*}{ Symptomatic treatment } & $\begin{array}{l}\text { Cholinesterase inhibitors, for example, donepezil }(1 \times 5-10 \mathrm{mg}) \text { or rivastigmine }(2-3 \times 6-12 \mathrm{mg}) \text {, } \\
\text { for dementia (evidence level } 1+\text {, recommendation grade A) }\end{array}$ \\
\hline & Memantine $(1 \times 5-20 \mathrm{mg})$ for behavioral symptoms (evidence level $1+$, recommendation grade A) \\
\hline & $\begin{array}{l}\text { Levodopa (3-4 × 100-200 mg) for akinetic-rigid symptoms (evidence level 2+, recommendation } \\
\text { grade B) }\end{array}$ \\
\hline & $\begin{array}{l}\text { Atypical neuroleptics, e.g., clozapine ( } 6.25-100 \mathrm{mg} / \text { day, } 2 / 3 \text { of this at nighttime) or quetiapine } \\
\text { (off-label, } 25-100 \mathrm{mg} \text { at nighttime), for psychosis (evidence level } 4 \text {, recommendation grade } 0 \text { ) }\end{array}$ \\
\hline
\end{tabular}

Evidence level 1 = randomized controlled study (studies); 2 = case-control study (studies); 3 = non-analytic case study (studies); 4 = expert opinion; recommendation grade $\mathrm{A}=$ strong recommendation [should]; $\mathrm{B}=$ recommendation; 0 = open recommendation [can]

$\mathrm{MRI}$, magnetic resonance imaging; SPECT, single photon emission computed tomography; PET, positron emission tomography

CBD. The different disease entities typically affect characteristic regions in the brain. The misfolding and aggregation of these proteins can lead to degeneration of the affected cell populations on the one hand, but on the other hand they can also facilitate their spread into anatomically connected regions of the brain and thereby enable disease progression (4). The increasingly better understanding of the pathophysiology provides new approaches to causally oriented treatment, in order to stop the progression of these currently incurable disorders (4).

\section{Clinical symptoms}

Firstly, we will describe the two parkinsonian syndromes characterized by synucleinopathy and then the two tauopathies, in descending order of prevalence.

\section{Dementia with Lewy bodies}

Epidemiology: DLB is the second most common form of progressive cognitive decline in old age due to neurodegeneration after dementia in Alzheimer's disease. Its prevalence in the population older than 65 years is approximately $0.4 \%$. Symptom onset usually occurs between the $50^{\text {th }}$ and $80^{\text {th }}$ year of life. Men are affected slightly more often than women $(5,6)$.

Clinical symptoms: The initial symptoms consist of a reduction in cognitive performance with fluctuating episodes of poor and better cognitive performance (Table 1). Deficits involve the naming of objects, verbal fluency, visuospatial abilities (as shown by the clock-drawing test), and executive functions. Executive problems become apparent in tasks requiring planning, shifting between strategies, organizing, and selfmonitoring. In contrast to Alzheimer's dementia, memory impairment is not a common or predominant feature in DLB at the early stage of the disease (7).

On the other hand, vivid, recurring or persistent visual hallucinations are frequent, as are delusions, lack of initiative and motivation, depressed moods, and anxiety (8). Akinetic-rigid movement disorder may already be present at the time of diagnosis, but develops over the course of the illness in the majority of cases. 


\begin{tabular}{l|l}
\hline Areas & Findings/recommendations \\
\hline Neuropathology & $\begin{array}{l}\text { Aggregates of a-synuclein in cytoplasm of oligodendrocytes (glial cytoplasmic inclusions) and } \\
\text { neurons in a typical distribution (cerebellum, pons, and basal ganglia) }\end{array}$ \\
\hline Clinical syndrome & $\begin{array}{l}\text { Dysautonomia: urinary incontinence, erectile dysfunction, orthostatic hypotension } \\
\text { At least one of the following syndromes: } \\
\text { - Parkinsonian syndrome (MSA-P, about } 60 \% \text { of cases, PPV about } 90 \%) \text { : bradykinesia with rigidity, } \\
\text { tremor, or postural instability } \\
\text { - Cerebellar syndrome (MSA-C, about } 40 \% \text { of cases, PPV about } 90 \%): \text { gait ataxia with cerebellar } \\
\text { dysarthria, limb ataxia, or cerebellar oculomotor dysfunction }\end{array}$
\end{tabular}

\begin{tabular}{l|l}
\hline MRI results & $\begin{array}{l}\text { Atrophy of putamen, middle cerebellar peduncle, pons, or cerebellum } \\
\text { Cross shaped hyperintensity in the pons (T2 axial) } \\
\text { Hypointense putamen with hyperintense rim (T2 axial) }\end{array}$
\end{tabular}

\section{Basic diagnostic evaluation Levodopa test: poor response to levodopa}

Schellong test: orthostatic drop in blood pressure after 3 minutes' standing up from supine position ( $\geq 20 \mathrm{~mm} \mathrm{Hg}$ systolic or $\geq 10 \mathrm{~mm} \mathrm{Hg}$ diastolic)

Urological examination: exclusion of other causes of erectile dysfunction and urinary incontinence

Extended diagnostic evaluation
${ }^{123}$ I-FP-CIT-SPECT $/{ }^{18} \mathrm{~F}$-Dopa-PET: symmetric striatal dopaminergic denervation

${ }^{99} \mathrm{TC}$-HMPAO-SPECT $/{ }^{18} \mathrm{FDG}$-PET: hypometabolism in putamen, brainstem, or cerebellum

${ }^{123}$ I-IBZM-SPECT $/{ }^{18} \mathrm{~F}$-DMFP-PET: symmetric postsynaptic, striatal degeneration

${ }^{123}$ I-MIBG-SPECT: intact cardiac noradrenergic innervation (DD PD with dysautonomia)

Oculomotor function: cerebellar pattern (saccadic pursuit movement, gaze-evoked or downbeat nystagmus)

Sleep laboratory: rapid eye movement (REM) sleep behavior disorder

Symptomatic treatment

Levodopa (3-4 × 100-200 mg): mild to moderate improvement of akinetic-rigid symptoms (evidence level 2-, recommendation grade $B$ )

Amantadine (3 × 100-200 mg): mild positive effect on akinetic-rigid symptoms (evidence level 1-, recommendation grade 0 )

Botulinum toxin A: positive effect on focal dystonia (evidence level 3 , recommendation grade 0 ) Droxydopa ( $2 \times 200-600 \mathrm{mg}$ ) (not approved in Germany for this indication): positive effect on orthostatic hypotension (evidence level 1 , recommendation grade $A$ )

Ephedrine $(3 \times 15-45 \mathrm{mg})$ : positive effect on orthostatic hypotension (evidence level 3 , recommendation grade 0 )

Midodrine $(3 \times 5-10 \mathrm{mg})$ : positive effect on orthostatic hypotension (evidence level $1+$, recommendation grade $A$ )

Fludrucortisone $(1-3 \times 0,1 \mathrm{mg})$ : positive effect on orthostatic hypotension (evidence level 3 , recommendation grade 0 )

Octreotide (25-50 mg s. c. 30 minutes before meals): positive effect on postprandial hypotension (evidence level 2-, recommendation grade 0)

Desmopressin (10-40 $\mu \mathrm{g}$ spray, 100-400 $\mu \mathrm{g}$ tablets): positive effect on nocturnal polyuria (evidence level 3 , recommendation grade 0 )

Oxybutinin $(2-3 \times 2.5-5 \mathrm{mg})$ : for urge incontinence (evidence level 4 , recommendation grade 0 )

Evidence level 1 = randomized controlled study (studies); 2 = case-control study (studies); 3 = non-analytic case study (studies); 4 = expert opinion; recommendation grade $\mathrm{A}=$ strong recommendation [should]; $\mathrm{B}=$ recommendation; $0=$ open recommendation [can]

MSA, multiple system atrophy; MRI, magnetic resonance imaging; PPV, positive predictive value; DD, differential diagnosis; PD, Parkinson's disease; s. c., subcutaneous; SPECT, single photon emission computed tomography; PET, positron emission tomography

Diagnosis: Typical clinical features include progressive dementia, fluctuating cognition, vivid visual hallucinations, and a parkinsonian syndrome (5).

Magnetic resonance imaging (MRI) may reveal atrophy of the caudate nucleus, putamen, and thalamus. In contrast to Alzheimer's dementia, little atrophy is seen in the cortex, while the medial temporal lobe in particular is not atrophied (eFigure) (9).
In specialized centers, functional brain imaging techniques can be used to improve diagnostic accuracy. These technologies include ${ }^{123}$ I-FP-CIT single-photon emission computed tomography (SPECT) for dopamine transporter visualization (10), positron emission tomography (PET) with ${ }^{18} \mathrm{~F}-\mathrm{FDG}$ as a tracer for the assessment of regional cerebral glucose metabolism (11), and PET in 


\section{Progressive supranuclear palsy}

\begin{tabular}{|c|c|}
\hline Areas & Findings/recommendations \\
\hline Neuropathology & $\begin{array}{l}\text { Aggregates of 4-repeat tau in astrocytes (tufts), oligodendrocytes (coiled bodies), and neurons } \\
\text { (neurofibrillar tangles) in typical distribution (predominant in basal ganglia and brainstem) }\end{array}$ \\
\hline \multirow[t]{6}{*}{ Clinical syndrome } & $\begin{array}{l}\text { Richardson's syndrome (PSP-RS, about } 40 \% \text { of cases, PPV about } 90 \% \text { ): symmetric, axial-oriented, } \\
\text { akinetic-rigid, levodopa resistant parkinsonian syndrome with early postural instability and vertical } \\
\text { supranuclear gaze palsy }\end{array}$ \\
\hline & $\begin{array}{l}\text { PSP with predominantly parkinsonian symptoms (PSP-P, about 20\%, of cases, PPV about 90\%): } \\
\text { asymmetric, limb-predominant, levodopa-responsive parkinsonian syndrome with late-onset } \\
\text { vertical supranuclear gaze palsy }\end{array}$ \\
\hline & $\begin{array}{l}\text { Pure akinesia with gait freezing (PAGF, }<5 \% \text { of cases, PPV about } 60 \% \text { ): gait freezing without rigidity, } \\
\text { without tremor, late-onset vertical supranuclear gaze palsy }\end{array}$ \\
\hline & $\begin{array}{l}\text { Behavioral variant of frontotemporal dementia (bvFTD, about } 15 \% \text { of cases, PPV low): apathy and } \\
\text { impaired executive functions ( }<6 \text { successive Luria sequences, applause sign), late-onset vertical } \\
\text { supranuclear gaze palsy }\end{array}$ \\
\hline & $\begin{array}{l}\text { Progressive non-fluent aphasia (PNFA, about } 5 \% \text { of cases, PPV low): non-fluent speech production } \\
\text { (<9 words beginning with S in } 60 \text { seconds) with agrammatism but spared single word comprehension }\end{array}$ \\
\hline & $\begin{array}{l}\text { Corticobasal syndrome (CBS, about } 10 \% \text { of cases, PPV about } 30 \% \text { ): at least one cortical symptom } \\
\text { (apraxia, loss of cortical sensitivity, alien limb phenomenon) and at least one extrapyramidal symptom } \\
\text { (akinesia, rigidity, dystonia, myoclonus) }\end{array}$ \\
\hline \multirow[t]{3}{*}{ MRI results } & Midbrain atrophy: axial anteroposterior diameter $<15 \mathrm{~mm}$ \\
\hline & Frontal lobe atrophy \\
\hline & $\begin{array}{l}\text { Exclude symptomatic causes, for example, vascular encephalopathy, normal pressure hydro- } \\
\text { cephalus, aqueductal stenosis, encephalitis, tumor }\end{array}$ \\
\hline \multirow[t]{3}{*}{ Basic diagnostic evaluation } & Levodopa test: poor responsiveness to levodopa \\
\hline & Oculomotor function: slowed, hypometric vertical saccades, frequent square wave jerks \\
\hline & $\begin{array}{l}\text { Neuropsychological tests: apathy, psychomotor retardation, reduced verbal fluency ( }<9 \text { words begin- } \\
\text { ning with S in } 60 \text { seconds), executive dysfunction ( }<6 \text { correct successive Luria sequences) }\end{array}$ \\
\hline \multirow{3}{*}{$\begin{array}{l}\text { Extended diagnostic } \\
\text { evaluation }\end{array}$} & ${ }^{123}$ I-FP-CIT-SPECT $/{ }^{18} \mathrm{~F}$-Dopa-PET: symmetric striatal dopaminergic denervation \\
\hline & ${ }^{99} \mathrm{TC}-\mathrm{HMPAO}-S P E C T /{ }^{18} \mathrm{FDG}-\mathrm{PET}$ : hypometabolism in frontal lobe and midbrain \\
\hline & ${ }^{123}$ |-IBZM-SPECT $/{ }^{18} \mathrm{~F}$-DMFP-PET: symmetric postsynaptic striatal degeneration \\
\hline \multirow[t]{6}{*}{ Symptomatic treatment } & $\begin{array}{l}\text { Levodopa (3-4 × } 100-200 \mathrm{mg}) \text { : mild to moderate improvement of akinetic-rigid symptoms } \\
\text { in about } 35 \% \text { of cases (evidence level } 2-\text {, recommendation grade B) }\end{array}$ \\
\hline & $\begin{array}{l}\text { Amantadine }(3 \times 100-200 \mathrm{mg}) \text { : mild to moderate improvement of akinetic-rigid symptoms } \\
\text { in about } 20 \% \text { of cases (evidence level } 3 \text {, recommendation grade } 0 \text { ) }\end{array}$ \\
\hline & $\begin{array}{l}\text { Amitriptyline }(1 \times 75-150 \mathrm{mg}) \text { : mild to moderate improvement of oculomotor deficits } \\
\text { in about } 35 \% \text { of cases (evidence level } 3 \text {, recommendation grade } 0)\end{array}$ \\
\hline & $\begin{array}{l}\text { Zolpidem }(1 \times 5-10 \mathrm{mg} \text { ): in impaired sleep (evidence level } 4 \text {, recommendation grade } 0 \text { ); } \\
\text { mild improvement of motor/oculomotor deficits in about } 20 \% \text { and } 40 \% \text { of cases (evidence level } 1-\text {, } \\
\text { recommendation grade } 0 \text { ) }\end{array}$ \\
\hline & $\begin{array}{l}\text { Coenzyme Q10 ( } 2 \times \text { daily , } \geq 2.5 \mu \mathrm{g} / \mathrm{mL} \text { serum concentration): mild improvement of motor and } \\
\text { neuropsychological symptoms (evidence level } 1+\text {, recommendation grade A) }\end{array}$ \\
\hline & $\begin{array}{l}\text { Botulinum toxin A: good improvement of focal dystonia in } 80 \% \text { of cases } \\
\text { (for example, apraxia of eye opening/blepharospasm in } 35 \% \text { of patients) (evidence level } 3 \text {, } \\
\text { recommendation grade 0) }\end{array}$ \\
\hline
\end{tabular}

Evidence level 1 = randomized controlled study (studies); 2 = case-control study (studies); 3 = non-analytic case study (studies); 4 = expert opinion; recommendation grade $\mathrm{A}=$ strong recommendation [should]; $\mathrm{B}=$ recommendation; 0 = open recommendation [can]

PSP, progressive supranuclear palsy; MRI, magnetic resonance imaging; PPV, positive predictive value; SPECT, single photon emission computed tomography; $\mathrm{PET}$, positron emission tomography

combination with other appropriate tracers for demonstrating beta-amyloid deposition (12). In addition to a dopaminergic deficit, patients show a characteristic pattern of hypometabolic areas, especially involving the occipital regions of the primary visual cortex and the visual association cortex. In contrast, the medial temporal lobe and the posterior cingulum are not affected. Deposits of beta-amyloid may be present, but are less pronounced than in Alzheimer's dementia (10-12). 


\begin{tabular}{|c|c|}
\hline Areas & Findings/recommendations \\
\hline Neuropathology & $\begin{array}{l}\text { Aggregates of 4-repeat tau in astrocytes (astrocytic plaques), oligodendrocytes } \\
\text { (coiled bodies), and neurons (neurofibrils) and, often, swollen achromatic neurons in typical } \\
\text { distribution (neocortex and basal ganglia) }\end{array}$ \\
\hline \multirow[t]{4}{*}{ Clinical syndrome } & $\begin{array}{l}\text { Corticobasal syndrome (CBS, about } 25 \% \text { of cases, PPV about } 25 \% \text { ): at least one cortical symptom } \\
\text { (apraxia, loss of cortical sensitivity, alien limb phenomenon) and at least one extrapyramidal symptom } \\
\text { (akinesia, rigidity, dystonia, myoclonus) }\end{array}$ \\
\hline & $\begin{array}{l}\text { Frontal behavioral-spatial syndrome (about } 10 \% \text { of cases, PPV low): executive dysfunction, } \\
\text { behavioral or personality changes, visuospatial deficits }\end{array}$ \\
\hline & $\begin{array}{l}\text { Richardson's syndrome (RS, about } 40 \% \text { of cases, PPV low): symmetric, axial, } \\
\text { akinetic-rigid, levodopa-resistant parkinsonian syndrome with early-onset postural instability and } \\
\text { vertical supranuclear gaze palsy }\end{array}$ \\
\hline & $\begin{array}{l}\text { Progressive non-fluent aphasia (PNFA, }<5 \% \text { of cases, PPV low): non-fluent speech production } \\
\text { ( }<9 \text { words beginning with } \mathrm{S} \text { in } 60 \text { seconds) with agrammatism while retaining understanding of indi- } \\
\text { vidual words }\end{array}$ \\
\hline MRI results & Parietal lobe atrophy: focal, mostly asymmetric \\
\hline \multirow[t]{2}{*}{ Basic diagnostic evaluation } & Levodopa test: poor responsiveness to levodopa \\
\hline & $\begin{array}{l}\text { Neuropsychological testing: for example, apraxia, pathological Frontal Assessment Battery (FAB), } \\
\text { reduced verbal fluency ( }<9 \text { words beginning with S in } 60 \text { seconds), executive dysfunction ( }<6 \text { correct } \\
\text { successive Luria sequences) }\end{array}$ \\
\hline \multirow{3}{*}{$\begin{array}{l}\text { Extended diagnostic } \\
\text { evaluation }\end{array}$} & ${ }^{123}$ I-FP-CIT-SPECT $/{ }^{18} \mathrm{~F}-\mathrm{Dopa}-\mathrm{PET}$ : asymmetric striatal dopaminergic denervation \\
\hline & ${ }^{99} \mathrm{TC}-\mathrm{HMPAO}-\mathrm{SPECT} /{ }^{18} \mathrm{FDG}-\mathrm{PET}$ : asymmetric hypometabolism in striatum and parietal cortex \\
\hline & ${ }^{123}$ I-IBZM-SPECT: asymmetric postsynaptic striatal degeneration \\
\hline \multirow[t]{5}{*}{ Symptomatic treatment } & $\begin{array}{l}\text { Levodopa ( } 3-4 \times 100-200 \mathrm{mg} \text { ): mild to moderate improvement of akinetic-rigid symptoms } \\
\text { in about } 35 \% \text { of cases (evidence level 3, recommendation grade B) }\end{array}$ \\
\hline & $\begin{array}{l}\text { Botulinum toxin A: good improvement of focal dystonia in } 70 \% \text { of cases } \\
\text { (evidence level } 3 \text {, recommendation grade B) }\end{array}$ \\
\hline & $\begin{array}{l}\text { Baclofen (up to } 40 \mathrm{mg} / \mathrm{day}) \text { : moderate improvement of dystonia in } 7 \% \text { of cases } \\
\text { (evidence level } 3 \text {, recommendation grade } 0 \text { ) }\end{array}$ \\
\hline & $\begin{array}{l}\text { Clonazepam ( } 2-6 \mathrm{mg} / \mathrm{day}) \text { : moderate improvement of myoclonus in about } 25 \% \text { of cases } \\
\text { (evidence level } 3 \text {, recommendation grade B) }\end{array}$ \\
\hline & $\begin{array}{l}\text { Propranolol ( } 80-120 \mathrm{mg} / \text { day, maximum dose } 320 \mathrm{mg} / \text { day): moderate improvement of action/postural } \\
\text { tremor in about } 20 \% \text { of cases (evidence level } 3 \text {, recommendation grade B) }\end{array}$ \\
\hline
\end{tabular}

Evidence level 1 = randomized controlled study (studies); 2 = case-control study (studies); 3 = non-analytic case study (studies); 4 = expert opinion; recommendation grade $\mathrm{A}=$ strong recommendation [should]; $\mathrm{B}=$ recommendation; 0 = open recommendation [can]

CBD, corticobasal degeneration; MRI, magnetic resonance imaging; PPV, positive predictive value; SPECT, single photon emission computed tomography; $\mathrm{PET}$, positron emission tomography

Differential diagnosis: The major differential diagnoses include Alzheimer's dementia and Parkinson's disease with dementia. DLB differs from Alzheimer's disease in respect to the following features: in DLB, memory impairments are relatively mild and occur at a later stage (Mini Mental State Examination); patients exhibit prominent visuo-spatial deficits (Clock Drawing Test), fluctuating cognitive performance; early parkinsonism, and mild atrophy of the medial temporal lobe including the hippocampus. They may also show rapid eye movement (REM) sleep behavior disorder (eFigure). DLB and PD with dementia form a spectrum lacking clear clinical or neuropathological boundaries. To distinguish between the two entities, the temporal sequence of symptom onset is usually employed. If cognitive impairments precede movement disorder by at least one year, the diagnosis of DLB is made. If motor disturbance occurs before or concomitantly with cognitive impairment, the condition is usually classified as Parkinson's disease with dementia (5).

Therapy: The treatment of DLB usually needs to address all three domains of the syndrome: cognitive deficits, neuropsychiatric symptoms, and movement disorder (13). A particular problem is posed by the fact that medication with levodopa can improve the parkinsonian symptoms but may worsen the neuropsychiatric symptoms. Dopamine agonists should not be used for treating movement disorder in DLB. Moreover, patients with DLB are particularly sensitive to the adverse effects of antipsychotic drugs. Table 1 shows the main options for symptomatic treatment. The evidence levels reported for the individual therapies refer to the 2008 guidelines of the Scottish Intercollegiate Guidelines Network (SIGN). The recommendation grades are 


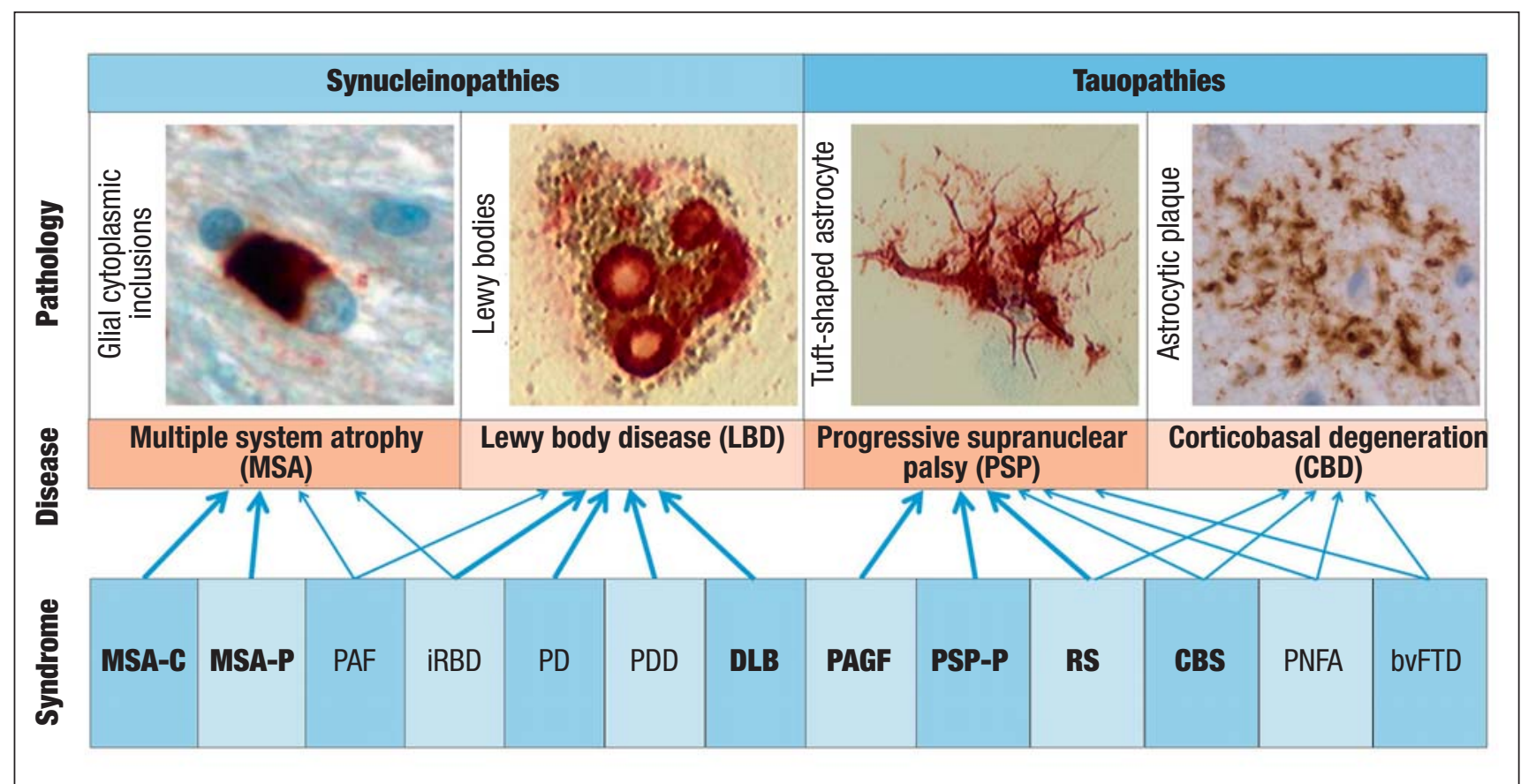

Figure 1: Disease definitions. Neurodegenerative parkinsonian syndromes are synucleinopathies or tauopathies which are defined by the intracellular aggregates of the alpha-synuclein or tau protein. The disease entities multiple system atrophy (MSA), dementia with Lewy bodies (DLB), progressive supranuclear palsy (PSP), and corticobasal degeneration (CBD) are characterized neuropathologically by glial cytoplasmic inclusions, Lewy bodies, tuft-shaped astrocytes, or astrocytic plaques, respectively. The resulting clinical syndromes: MSA with predominantly cerebellar symptoms (MSA-C), MSA with predominantly parkinsonian symptoms (MSA-P), pure autonomic failure (PAF), idiopathic rapid eye movement sleep behavior disorder (iRBD), Parkinson's disease (PD), Parkinson's disease with dementia (PDD), dementia with Lewy bodies (DLB), pure akinesia with gait freezing (PAGF), PSP with predominantly parkinsonian symptoms (PSP-P), Richardson's syndrome (RS), corticobasal syndrome (CBS), progressive non-fluent aphasia (PNFA), or the behavioral variant of frontotemporal dementia (bvFTD). PD and PDD are the most common parkinsonian syndromes. From a clinical perspective the syndromes in bold print—MSA-C, MSA-P, DLB, PAGF, PSP-P, RS, and CBS—are classed among the atypical parkinsonian syndromes. The other syndromes are characterized primarily by non-motor symptoms. The estimated positive predictive value (PPV) of the clinical syndromes for an underlying neuropathological disease entity is indicated by arrows (bold: high PPV; regular: medium to low PPV)

reproduced in accordance with the Association of the Scientific Medical Societies in Germany (AWMF) 2012. These definitions are also used for the other atypical parkinsonian syndromes described in the following chapters.

\section{Multiple system atrophy}

Epidemiology: Multiple system atrophy (MSA) has a prevalence of about 5/100 000. The mean age at disease onset is in the sixth decade of life, and the sex distribution is even. After an average of 6 to 10 years, patients die mostly from aspiration or nocturnal cardiorespiratory arrest (14).

Clinical symptoms: MSA has two different subtypes, either with predominant parkinsonism (MSA-P) (in Europe, this applies to $60 \%$ of cases) or with predominant cerebellar symptoms (MSA-C, 40\%). In addition to motor impairment, vegetative symptoms are an obligatory component of MSA - especially urinary incontinence, erectile dysfunction, or orthostatic hypotension (Table 2). Isolated pure autonomic failure (PAF) may precede the motor impairments in MSA.

A hypokinetic-rigid parkinsonian syndrome is dominant in MSA-P, but as a rule its presentation tends to be more symmetrical and less responsive to levodopa than in PD. The classical, slow, pill-rolling resting tremor of PD is rare in MSA. What is mostly found is an irregular, higher-frequency postural tremor.

In MSA-C, the most common symptom is gait ataxia with wide-based movements. Furthermore, ataxia of the limbs is common, as are cerebellar oculomotor impairments, scanning dysarthria, and intention tremor.

Some further symptoms are typical of MSA but do not affect every patient and can occur in both predominance types (15). Patients in advanced stages of the disease often have dysarthria, inspirational stridor, and dysphagia, for example. Extrapyramidal signs are seen in $30-50 \%$ of patients with MSA, but not in PD patients. Focal dystonias and posture abnormalities (antecollis, Pisa syndrome, contractures of the hands/feet) are also common (14). Many patients with MSA have a comorbid diagnosis of REM sleep behavior disorder (14).

Diagnosis: The diagnostic criteria of MSA were revised in 2008 (16). The diagnosis requires at least one symptom of vegetative dysfunction (orthostatic hypotension, urinary incontinence, erectile dysfunction) after the exclusion of symptomatic causes. Furthermore, 

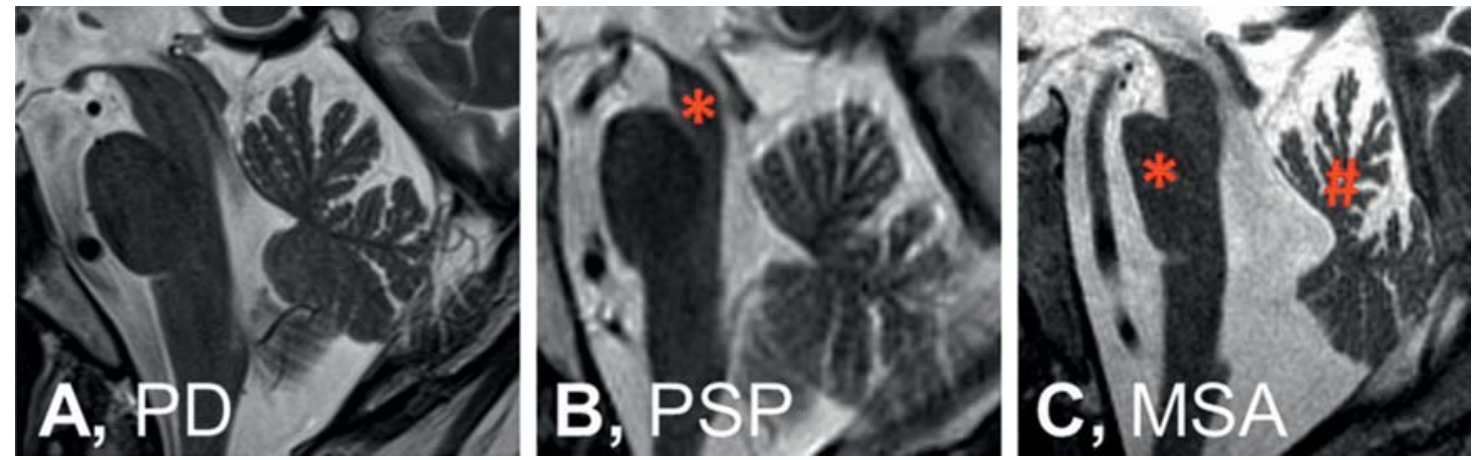

Figure 2: Imaging results، On magnetic resonance imaging, the midsagittal plane of the brainstem does not show a specific atrophy pattern in Parkinson's disease (PD) (A), whereas in progressive supranuclear palsy (PSP) (B) midbrain atrophy (*) is visible, and in multiple system atrophy (MSA) (C), atrophy of the pons $\left(^{*}\right)$ and in the upper portion of the cerebellar vermis (\#) can be seen. Further characteristic imaging

findings of atypical parkinsonian syndromes are shown in the eFigure

sporadic progressive parkinsonian symptoms (MSA-P) or ataxia (MSA-C) and at least one further typical symptom or a characteristic imaging finding are needed. Atrophy in the putamen, the middle cerebellar peduncle, the pons, and the cerebellum are visible on MRI (Figure 2), and hypometabolism in the putamen, brain stem, or cerebellum on FDG-PET scans. Not included in the diagnostic criteria but still indicative of MSA are signaling anomalies in T2-weighted MRI scans with 1.5 Tesla (eFigure): a cross-shaped hypointensity in the pons ("hot cross bun" sign) and a hypointense putamen with a hyperintense rim (putaminal rim sign) (17).

Therapy: In about one-third of patients, treatment with levodopa will improve the hypokinetic-rigid symptoms in MSA-P (18). To date, no effective treatment exists for ataxia. Symptomatic treatment of the vegetative symptoms is recommended (13) (Table 2), as these notably impair patients' quality of life (19). Furthermore, speech therapeutic, occupational therapeutic, and physiotherapeutic measures are indicated in order to maintain patients' independence.

\section{Progressive supranuclear palsy}

Epidemiology: Progressive supranuclear palsy has a prevalence of 5-10/100 000 persons. The mean age at onset is 65 years. Patients die after an average of 8 years, often as a result of aspiration. The sex ratio is for the most part evenly balanced (20).

Clinical symptoms: The clinical manifestations of PSP are diverse (Table 3). The most common of these (ca 40\%) is Richardson's syndrome, with levodoparesistant akinetic-rigid symptoms affecting the axial muscles, a tendency to fall backwards that occurs early in the disease course, and vertical gaze paresis (21). Patients are unable to move their eyes upwards or downwards at will, but vertical eye movements can still be triggered by the vestibulo-ocular reflex (passive head movement applied by the investigator). A frontal lobe syndrome is also typical, with apathy, impaired executive functions, and a positive "applause sign" (the inability to stop clapping after being asked to imitate the examiner's three handclaps). Additionally, the Luria test yields a pathological result: patients are unable to correctly perform the sequence of hand-fist-palm at least six times in succession. Verbal fluency is reduced to $<9$ words beginning with $\mathrm{S}$ in 60 seconds. Spastic (pseudobulbar) speech and swallowing impairment is also characteristic. Often PSP is initially characterized by asymmetric levodopa-responsive parkinsonism (PSP-P, about 20\%), which is clinically indistinguishable from Parkinson's disease, until the later onset of vertical gaze paresis. A rare syndrome with sudden and transient gait freezing without accompanying rigidity or tremor is known as pure akinesia with gait freezing (PAGF, $<5 \%$ ) and is considered typical of an underlying PSP neuropathology. Sometimes the onset of the disease may be dominated by clinical symptoms in accordance with the behavioral variant of frontotemporal dementia (bvFTD, 15\%) or progressive non-fluent aphasia (PNFA. 5\%), which can be distinguished from other forms of frontotemporal dementia only once oculomotor problems appear. Similarly, PSP pathology can clinically trigger a corticobasal syndrome (CBS, 10\%), which is described in the chapter on CBD (21).

Diagnosis: The current criteria of the National Institute of Neurological Disorders and Stroke (NINDS) and the Society for Progressive Supranuclear Palsy (SPSP) for the diagnosis of PSP (22) are based on the clinical confirmation of the tendency to falls and oculomotor impairments. They are thus very sensitive for Richardson's syndrome, but less suitable for detecting the other clinical courses that PSP takes (21). MRI will reveal midbrain and frontal lobe atrophy (Figure 2) (23). The parkinsonian symptoms generally improve only slightly in the levodopa test. In case of doubt, nuclear medicine methods can be used to confirm symmetric presynaptic nigrostriatal dopaminergic denervation (for example, FP-CIT-SPECT), postsynaptic striatal degeneration (for example, IBZM-SPECT), or hypometabolism in the frontal and midbrain regions (FDG-PET) to ascertain the diagnosis. 
Therapy: The treatment of PSP is currently exclusively symptomatic (Table 3$)(13,20)$. Therapeutic target symptoms include akinetic-rigid symptoms, oculomotor impairments, neuropsychological deficits, and the occasionally occurring dystonia and sleep impairment. The fundamentals of pharmacological treatment are summarized in Table 3. Furthermore, speech therapy and physiotherapy are indicated to prevent aspiration and falls.

\section{Corticobasal degeneration}

The term corticobasal degeneration (CBD) is reserved for the neuropathological diagnosis. Clinically, CBD mostly manifests with a corticobasal syndrome (CBS) (24). Patients with CBD pathology may, however, also have other clinical syndromes than CBS (24) (Table 4). Similarly, patients with clinical CBS may in terms of neuropathology also have underlying PSP, Alzheimer's disease, or other pathologies (25). The clinicopathological assignment is therefore possible to a very limited degree only, which underlines the necessity of a strict distinction of the neuropathological diagnosis of CBD from the clinical diagnosis of CBS.

Epidemiology: The prevalence of $\mathrm{CBD}$ is about $1 / 100000$. It usually affects persons in their $6^{\text {th }}$ and $7^{\text {th }}$ decades of life and affects both sexes in equal measure. Patients die after an average of eight years with the disease, mostly from aspiration due to dysphagia (26).

Clinical symptoms: CBS is a progressive constellation of symptoms that comprise functional damage to the basal ganglia and the cerebral cortex and mostly appear asymmetrically (27).

The basal ganglia symptoms include akinesia, rigidity, dystonia, and myoclonus. The hypokineticrigid parkinsonian syndrome is typically resistant to levodopa. Tremor may be present, which is superimposed on myoclonus and therefore appear irregular and jerky. As the disease progresses, many patients develop a characteristic, fixed dystonia-related posture of the affected arm, which usually consists of flexion of the hand and forearm and adduction of the upper arm at the shoulder joint (28). During the disease course, most patients develop rigid immobility in just a few years and require care.

The following cortical symptoms can develop:

- Apraxia (difficulty in executing intentional movements despite intact upper and lower motor neuron function)

- Cortical sensory loss (although primary sensation is intact, topographic assignment is impaired in two-point discrimination, graphesthesia, stereognosis)

- Alien limb phenomenon (experiencing one's limb as not belonging to one's body)

- Pyramidal signs

- Behavioral disorders

- Aphasia (24).

Diagnosis: The current consensus criteria (24) describe different clinical phenotypes that may be associated with CBD pathology (Table 4). The corticoba- sal syndrome is defined as described above. Imaging techniques can be used to demonstrate asymmetric parietal atrophy (eFigure) and hypometabolism, as well as presynaptic and postsynaptic nigrostriatal degeneration.

Therapy: Symptomatic treatment (13) (Table 4) of the akinetic-rigid syndrome with levodopa yields a slight transient improvement in about $30 \%$ of patients with CBD. Myoclonus responds to clonazepam, among others. In focal dystonia, the local injection of botulinum toxin may be useful (28). Anticholinergic drugs are useful for tremors. Physiotherapy, occupational therapy, and speech therapy should also be prescribed.

\section{Outlook}

For a long time, attempts have been made in atypical parkinsonism to diagnose molecular-neuropathologically defined disease entities on the basis of neurological-psychiatric symptom constellations and MRI findings. The clinical syndromes and patterns of regional cerebral atrophy (Figure 2) and functional impairments confirmed by nuclear medical techniques correlate well with each other (eFigure). As it turns out, however, different molecular pathologies can trigger overlapping syndromes and imaging results (Figure 1). CBS, for example, may be due to underlying CBD, PSP, or other pathologies (24). Conversely, PSP pathology may manifest with a multitude of syndromes (21). For this reason, symptoms often do not allow satisfactory attribution to one particular disease entity. Since the established therapies aim for symptom alleviation by means of neurotransmitter modulation, a syndromal classification has been sufficient for routine clinical practice. However, treatment approaches to date have remained unsatisfactory in terms of symptom control and do not delay the progress of the disease. Luckily, spectacular insights into the disease mechanisms have been achieved in recent years, so that causal therapeutic approaches can be studied clinically. These include modulators of pathological protein misfolding, such as the substance Anle138b and antibodies to alpha-synuclein or tau $(29,30)$. Interventions against defined molecular target structures do, however, require a diagnosis based on molecular pathology, to confirm the presence of the molecular target structures for causal therapy in the individual patient. For this reason, we are currently faced with the challenge of defining and diagnosing neurodegenerative diseases on the basis of their molecular pathologies, not on the basis of clinical syndromes as entities. On this background it is to be welcomed that new diagnostic tools have been developed-for example, tau-PET (eFigure). In this way, molecular processes that could be detected only by neuropathological examination so far, can be put to diagnostic use-for example, deposits of the tau protein. We can therefore be optimistic that relevant innovations will be achieved in the coming years in dealing with these rapidly progressive, fatal diseases. 


\section{KEY MESSAGES}

- In distinction from Parkinson's disease, atypical parkinsonism occurs as four diseases in particular: dementia with Lewy bodies (DLB), multiple system atrophy (MSA), progressive supranuclear palsy (PSP), and corticobasal degeneration (CBD).

- The current treatment of the atypical parkinsonian syndromes is symptomatic

- A detailed and regular clinical examination is important in order to identify problems requiring treatment in good time.

- The syndrome- and imaging-based diagnostic evaluation of the atypical parkinsonian syndromes in specialized centers allows good, but not perfect, classification of the neuropathologically defined disease entities.

- Promising molecular-based diagnostic methods, such as tau position emission tomography (PET), and therapeutic options, such as tau/synuclein antibodies are currently under clinical development.

\section{Acknowledgments}

Günter Höglinger was supported by the German Research Foundation (DFG, H02402/6-2). We thank Dr Maximilian Petzig of the Department of Neuroradiology, Ludwig Maximilian University of Munich, for the MRI images. We thank Prof Alexander Drzezga of the Clinic and Outpatient Clinic of Nuclear Medicine, University Hospital Cologne, for the tau-PET images.

\section{Conflict of interest statement \\ Dr Levin has received study support (third party funds) from Parkinson Fonds Deutschland $\mathrm{gGmbH}$ (a private organization that provides grants for research into Parkinson's disease) and lecture fees from Bayer Healthcare and MSD. \\ Prof Giese holds stocks and shares in and has personal links with MODAG. He also holds shares in the patent "EP2307381" and diverse national secondary patents. \\ Prof Höglinger is an advisory board member for Asceneuron, Bristol-Myers Squibb, Roche and UCB Pharma. He has received lecture fees from Abbvie, Bristol-Myers Squibb, Elan, Noscira, Roche, Sellas, Teva, and UCB Pharma.}

The remaining authors declare that no conflict of interests exists.

Manuscript received on 11 June 2015, revised version accepted on 20 0ctober 2015

Translated from the original German by Birte Twisselmann, $\mathrm{PhD}$

\section{REFERENCES}

1. Dickson DW: Parkinson's disease and parkinsonism: neuropathology. Cold Spring Harb Perspect Med 2012; 2. pii: a009258.

2. Wakabayashi K, Takahashi H: Pathological heterogeneity in progressive supranuclear palsy and corticobasal degeneration. Neuropathology 2004; 24: 79-86.

3. Jellinger KA. Neuropathological aspects of Alzheimer disease, Parkinson disease and frontotemporal dementia. Neurodegener Dis 2008; 5: 118-21.

4. Lim J, Yue Z. Neuronal aggregates: formation, clearance, and spreading. Dev Cell 2015; 32: 491-501

5. McKeith IG, Dickson DW, Lowe J, et al., Consortium on DLB: Diagnosis and management of dementia with Lewy bodies: third report of the DLK Consortium. Neurology 2005; 65: 1863-72.

6. Vann Jones SA, O'Brien JT: The prevalence and incidence of dementia with Lewy bodies: a systematic review of population and clinical studies. Psychol Med 2014; 44: 673-83.

7. Karantzoulis S, Galvin JE: Distinguishing Alzheimer's disease from other major forms of dementia. Expert Rev Neurother 2011; 11: 1579-91.

8. Geser F, Wenning GK, Poewe W, McKeith I: How to diagnose dementia with Lewy bodies: state of the art. Mov Disord 2005; 20 Suppl 12: S11-20.
9. Watson R, Blamire AM, O'Brien JT: Magnetic resonance imaging in lewy body dementias. Dement Geriatr Cogn Disord 2009; 28: 493-506.

10. Mak E, Su L, Williams GB, O'Brien JT: Neuroimaging characteristics of dementia with Lewy bodies. Alzheimers Res Ther 2014; 6: 18.

11. Perneczky R, Drzezga A, Boecker H, Förstl H, Kurz A, Häussermann P: Cerebral metabolic dysfunction in patients with dementia with Lewy bodies and visual hallucinations. Dement Geriatr Cogn Disord 2008; 25: 531-8.

12. Donaghy P, Thomas AJ, O'Brien JT: Amyloid PET imaging in Lewy body disorders. Am J Geriatr Psychiatry 2015; 23: 23-37.

13. Eggert K; Oertel W, Reichmann $\mathrm{H}$, et al.: Leitlinien für Diagnostik und Therapie in der Neurologie: Parkinson-Syndrome. Deutsche Gesellschaft für Neurologie 2012.

14. Fanciulli A, Wenning GK: Multiple-system atrophy. N Engl J Med 2015; 372 : 1375-6.

15. Köllensperger M, Geser F, Seppi K, et al., European MSA Study Group: Red flags for multiple system atrophy. Mov Disord 2008; 23: 1093-9.

16. Gilman S, Wenning GK, Low PA, et al.: Second consensus statement on the diagnosis of multiple system atrophy. Neurology 2008; 71: 670-6.

17. Mahlknecht P, Schocke M, Seppi K: [Differential diagnosis of parkinsonian syndromes using MRI]. Nervenarzt 2010; 81: 1168-79.

18. Constantinescu R, Richard I, Kurlan R: Levodopa responsiveness in disorders with parkinsonism: a review of the literature. Mov Disord 2007; 22: 2141-8.

19. Schrag A, Geser F, Stampfer-Kountchev M, et al., European MSA-Study Group: Health-related quality of life in multiple system atrophy. Mov Disord 2006; 21: 809-15.

20. Stamelou M, de Silva R, Arias-Carrión 0, et al.: Rational therapeutic approaches to progressive supranuclear palsy. Brain 2010; 133: 1578-90.

21. Respondek G, Stamelou M, Kurz C, et al.: Movement Disorder Society-endorsed PSP Study Group. The phenotypic spectrum of progressive supranuclear palsy: a retrospective multicenter study of 100 definite cases. Mov Disord 2014; 29: 1758-66.

22. Litvan I, Agid Y, Calne D, et al.: Clinical research criteria for the diagnosis of progressive supranuclear palsy (Steele-Richardson-Olszewski syndrome): report of the NINDS-SPSP international workshop. Neurology 1996; 47: 1-9.

23. Stamelou M, Knake S, Oertel WH, Höglinger GU: Magnetic resonance imaging in progressive supranuclear palsy. J Neurol 2011; 258: 549-58.

24. Armstrong MJ, Litvan I, Lang AE, et al.: Criteria for the diagnosis of corticobasal degeneration. Neurology 2013; 80: 496-503.

25. Ling H, O'Sullivan SS, Holton JL, et al.: Does corticobasal degeneration exist? A clinicopathological re-evaluation. Brain 2010; 133: 2045-57.

26. Wenning GK, Litvan I, Jankovic J, et al.: Natural history and survival of 14 patients with corticobasal degeneration confirmed at postmortem examination. J Neurol Neurosurg Psychiatry 1998; 64: 184-9.

27. Rebeiz JJ, Kolodny EH, Richardson EP Jr: Corticodentatonigral degeneration with neuronal achromasia: a progressive disorder of late adult life. Trans Am Neurol Assoc 1967; 92: 23-6.

28. Vanek Z, Jankovic J: Dystonia in corticobasal degeneration. Mov Disord 2001; 16: $252-7$

29. Wagner J, Ryazanov S, Leonov A, et al.: Anle138b: a novel oligomer modulator for disease-modifying therapy of neurodegenerative diseases such as prion and Parkinson's disease. Acta Neuropathol 2013; 125: 795-813.

30. Castillo-Carranza DL, Guerrero-Muñoz MJ, Sengupta U, et al.: Tau immunotherapy modulates both pathological tau and upstream amyloid pathology in an Alzheimer's disease mouse model. J Neurosci 2015; 35: 4857-68.

\section{Corresponding author:}

Prof. Dr. med. Günter U. Höglinger

Technische Universität München (TUM) und

Deutsches Zentrum für Neurodegenerative Erkrankungen e. V. (DZNE)

Klinik für Neurologie und Lehrstuhl für Translationale Neurodegeneration

Feodor-Lynen Str. 17

81377 München, Germany

Guenter.Hoeglinger@tum.de

Supplementary materia

eFigure:

www.aerzteblatt-international de/16m0061 
Supplementary material to:

\section{The Differential Diagnosis and Treatment of Atypical Parkinsonism}

Johannes Levin, Alexander Kurz, Thomas Arzberger, Armin Giese, and Günter U. Höglinger

Dtsch Arztebl Int 2016; 113: 61-9. DOI: 10.3238/arztebl.2016.0061
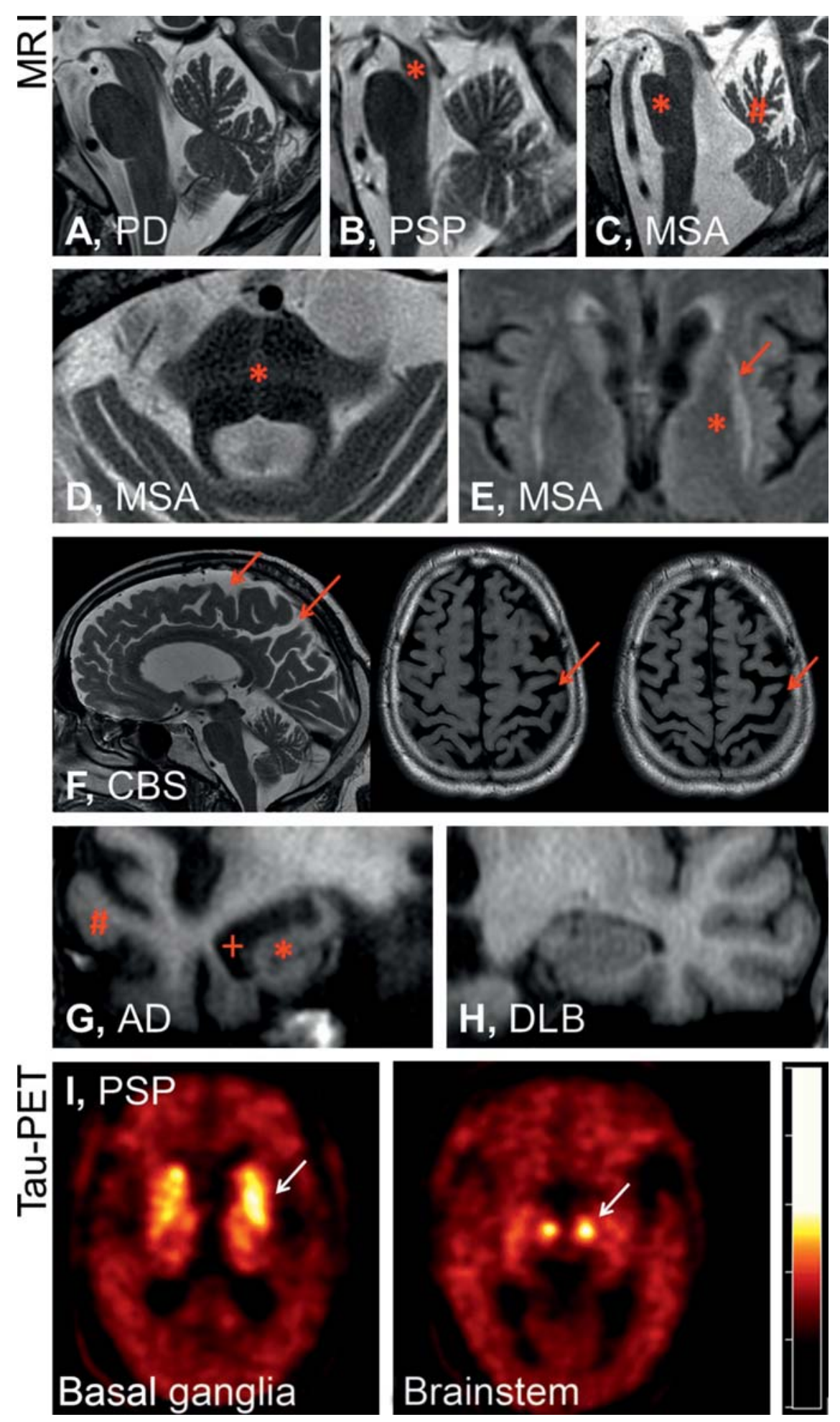